\title{
Developing regional climate change scenarios for use in assessment of effects on human health and disease
}

\author{
F. Giorgi ${ }^{1, *}$, N. Diffenbaugh ${ }^{2}$ \\ ${ }^{1}$ International Centre for Theoretical Physics (ICTP), PO Box 586, 34100 Trieste, Italy \\ ${ }^{2}$ Purdue Climate Change Research Center and Department of Earth and Atmospheric Sciences, Purdue University, \\ 550 Stadium Mall Drive, West Lafayette, Indiana 47907-2051, USA
}

\begin{abstract}
Climatic changes induced by anthropogenic increases in atmospheric concentrations of greenhouse gases could have substantial effects on human health and the dynamics of vector-borne diseases. In order to assess such impacts, climate change information is needed at the regional scale. In the present paper we provide a discussion of the tools and methodologies available today to produce regional climate change information along with a review of the more robust regional climate change patterns indicated by the latest-generation model simulations. We also present an analysis of the uncertainties underlying the simulation of climate change. The discussion is presented within the context of the use of climate change scenarios at the global to regional scale for studies of human health and disease impacts.
\end{abstract}

KEY WORDS: Climate change $\cdot$ Human health impacts $\cdot$ Disease impacts $\cdot$ Temperature change · Precipitation change $\cdot$ Climate scenarios

Resale or republication not permitted without written consent of the publisher

\section{INTRODUCTION}

It is by now evident that increased concentrations of anthropogenic greenhouse gases (GHG) have affected the Earth's climate in the 20th century and will continue to modify it in the 21st century (IPCC 2007). Increased GHG forcing influences a range of climatic variables and statistics, such as global and regional mean temperature and precipitation, interseasonal and interannual variability, wind patterns, cloudiness, and occurrence of extreme events (IPCC 2007). These changes can affect human health and the spread of vector-borne diseases (Patz et al. 2005, McMichael et al. 2006). For example, increased frequency of heat waves and droughts would enhance the occurrence of heat-stress and pollution-related pathologies (e.g. Kalkstein \& Greene 1997, Schar et al. 2004, Patz et al. 2005). Additionally, although potential impacts of warming on infectious disease transmission are not yet entirely understood (e.g. Rogers \& Randolph 2000, Zell
2004), higher temperatures and changes in seasonality could influence infectious diseases by enhancing pathogen survival and development (Harvell et al. 2002), along with vector cold-season survival (Marra et al. 2004). Present climate relationships have been identified for vector-borne diseases such as malaria (e.g. Zhou et al. 2004), cholera (e.g. Pascual et al. 2000), and dengue fever (e.g. Gagnon et al. 2001). Should these relationships persist, changes in climate could influence the geographical and temporal distribution of such diseases. Furthermore, changes in seasonality, interannual variability, and extremes might influence the non-linear dynamics of host-parasite interactions to yield unexpected responses.

Developing climate change scenarios is, thus, an important component of understanding human health and disease under global warming conditions, with critical implications for climate change adaptation and mitigation. In addition, climate change can show pronounced regional variability, which could affect the 
geographical distribution and evolution of current diseases. Climate change information is, thus, needed at the regional scale in order to provide locally specific information for use in impact assessment studies. In addition to coupled atmosphere-ocean general circulation models (AOGCMs) traditionally used for climate change simulation, today we have a range of 'regionalization' techniques capable of providing fine-scale regional and local climate information (Giorgi et al. 2001a): these include uniform and variable resolution atmospheric general circulation models (AGCMs; Cubasch et al. 1995, Deque \& Piedelievre 1995), regional climate models (RCMs; Giorgi 2006), and statistical downscaling techniques (Hewitson \& Crane 1996).

Moreover, it is increasingly clear that in order to account for different sources of uncertainty, the climate change prediction problem needs to be addressed using data compounded from large ensembles of climate change simulations (e.g. Giorgi 2005a). In this regard, the availability of increasingly powerful computing platforms and of a wide variety of modeling systems has enabled large ensembles that allow exploration of the climate change phase space and production of probability density functions (PDFs) of climate change variables (e.g. Murphy et al. 2004, Stainforth et al. 2005).

With these premises, we present a review of methodologies available to produce regional climate change information, along with an analysis of the climate change patterns emerging from the latest-generation model projections and associated uncertainties. The emphasis of the discussion is on climate variables of particular interest to disease prevalence, i.e. temperature, precipitation, and circulation patterns.

\section{CLIMATE MODELS FROM THE GLOBAL TO THE REGIONAL SCALE}

AOGCMs are the basic tools used for the simulation of climate change under increased GHG forcing. Stateof-the-art AOGCMs typically include fully coupled atmospheric, ocean, sea-ice, and land vegetation/ hydrology components. Most models also include the representation of the effects of atmospheric aerosols, in particular sulfates and carbonaceous aerosols. A subset of models include also representation of the carbon cycle and related feedbacks on the atmospheric GHG concentration (Friedlingstein et al. 2006). In fact, the global modeling community is increasingly moving towards the development of Earth system models that include interactive biosphere, biogeochemistry, and atmospheric chemistry components.

AOGCMs have been used for many years in a wide variety of applications, from weather and seasonal-tointerannual prediction to paleoclimate and climate change simulation. Some of the underlying issues differ fundamentally between these applications. Weather prediction is an initial value problem, where, given some initial conditions of the climate system, an attempt is made to forecast how this system will evolve over the short term. Conversely, climate change prediction is primarily (although not exclusively) a boundary value problem, in which an attempt is made to predict the response of the climate system, as defined by certain climate statistics (e.g. mean precipitation or frequency of extremes), to changes in external forcings (e.g. GHG anthropogenic emissions or solar irradiance).

On the other hand, long-term climate is composed of the statistics of short-term weather events, and indeed the changes in the frequency and intensity of shortterm events, such as severe storms, heat waves, and droughts, can be critical in determining specific impacts of climate change. It might thus be argued that a climate model should be successful in reproducing phenomena on a wide range of spatial and temporal scales. This has led to the recent development of the 'seamless' prediction concept (J. Shukla pers. comm.), by which the same modeling system should be able to operate successfully for the full range of prediction problems, from weather and seasonal prediction to long-term climate simulation.

AOGCMs have traditionally been successful in reproducing the basic characteristics of the general circulation of the atmosphere, and a steady improvement has been observed in successive generations of models. For example, Randall et al. (2007) show that the CMIP3 model ensemble recently completed in support of the IPCC fourth assessment report (http://wwwpcmdi.llnl.gov) reproduces the basic observed temperature and precipitation patterns, as well as the mean characteristics of jet streams and temperature gradients in the troposphere. The models are generally less successful in simulating higher order statistics (e.g. distributions of daily precipitation events) and internal modes of variability (e.g. El Niño-Southern Oscillation [ENSO]) (Collins et al. 2005), although an improvement in these aspects has also occurred (Randall et al. 2007).

A fundamental issue concerning the use of AOGCMs to provide regional climate change scenarios is that of horizontal resolution. Despite the recent increase in computing power, AOGCMs are still run at horizontal grid intervals of 100 to $300 \mathrm{~km}$. While this resolution is sufficient to capture processes and climate statistics down to the sub-continental scale (approximately a few thousand kilometers), it is not suitable for finer regional and local scales. This has led to the development of the regionalization techniques mentioned in Section 1. Each of these techniques has advantages 
and limitations and has undergone tremendous development (Giorgi et al. 2001a). In particular, it is now possible to produce multi-decadal climate change information at scales of a few tens of kilometers, which allows us to capture, much better than in the past, the effects of local topographical, coastline, and land-use features (Diffenbaugh et al. 2005, 2007, Gao et al. 2006) as well as the structure and statistics of extreme weather events (e.g. Huntingford 2003).

\section{UNCERTAINTIES IN THE GENERATION OF REGIONAL CLIMATE CHANGE INFORMATION}

The issue of uncertainty is key to the generation of climate change scenarios. The cascade of uncertainty in climate change prediction has been examined, for example, by Mearns et al. (2001) and Giorgi (2005a) (Fig. 1). At the top of the cascade is the uncertainty in emissions due to different assumptions of socioeconomic and technological developments. This uncertainty has been explored by developing a range of GHG and aerosol emission scenarios (see IPCC 2000), which are still currently used to produce global climate change projections. The second step of the cascade consists of the conversion of emissions into concentrations, which is usually carried out through the use of biogeochemical models. Within the IPCC scenario range, $\mathrm{CO}_{2}$ concentrations by the year 2100 range from

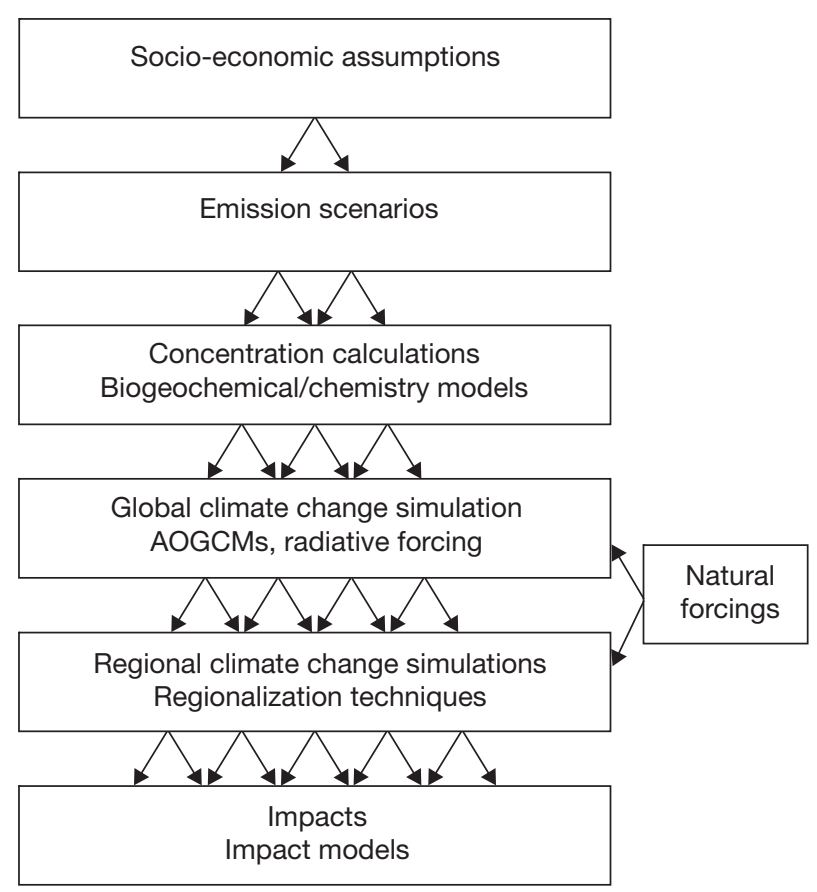

Fig. 1. Cascade of uncertainty in climate change prediction. Adapted from Giorgi (2005a). AOGCM: atmosphere-ocean general circulation model values of about 550 to 950 ppm (IPCC 2000), i.e. a factor slightly $<2$.

The pathway of GHG concentrations is used as input to AOGCMs to produce global climate change projections. Typically, an AOGCM 'transient' climate change projection consists of a simulation nominally starting at the beginning of the industrial era (for example 1860) and ending at some time in the future (e.g. 2100). Trends in observed anthropogenic (GHG, aerosol) and natural (solar input, volcanic activity) forcings are used for the historical period (e.g. up to 2005), while GHG and aerosol concentration (or emission) scenarios are used for the future period. At present, future climate simulations do not include effects of future changes in solar irradiance and volcanic eruptions. The beginning of the simulation is selected from a long-term 'control run' in which the AOGCM reaches internal dynamical equilibrium under preindustrial forcings.

Uncertainties in AOGCM projections originate essentially from 2 types of sources. The first can be referred to as 'configuration uncertainty' (Giorgi 2005a). It derives from the fact that different AOGCMs employ different resolutions, dynamical schemes, and physics parameterizations or parameter values. As a result, models employing different configurations generally respond differently to the same GHG forcing, thereby generating an uncertainty in the projection.

The second source of AOGCM uncertainty is related to the internal model variability, which, in turn, is a reflection of the non-linear and chaotic nature of the climate system (Giorgi 2005a). This uncertainty stems from the fact that, although the atmosphere responds quickly to external forcings (order of months to years), the oceans and land-surface conditions have much longer response times, up to centuries and millennia. Therefore, it is possible that the response of the climate system to the GHG forcing depends on the initial state of the ocean and land-surface conditions. This uncertainty can be explored by starting the AOGCM transient simulation at different times within the control run and thus producing an ensemble of realizations.

Once the AOGCM global projections are completed, they can be reduced to finer scales using 1 or more regionalization techniques, leading to a further level of uncertainty in the regional climate change projection. This cascade of uncertainty is then reflected on uncertainties in impact assessment methodologies, which, in turn, affect uncertainties in adaptation and mitigation options and may feed back into the climate change prediction (Mearns et al. 2001).

In general, for global to regional temperature and precipitation projections, the uncertainty related to scenarios and model configuration are dominant (e.g. IPCC 2001). The uncertainty related to internal model 
variability is generally small for mean changes, but it becomes more significant at regional scales and for changes in higher order statistical moments (e.g. interannual to interdecadal variability) (Giorgi \& Francisco 2000).

Because of the uncertainties underlying the climate change issue and the highly non-linear nature of the climate system, the problem of climate change prediction needs to be approached in a probabilistic way (Giorgi 2005a). In other words, a climate prediction should attempt to provide an estimate of the range of future climate pathways implied by the underlying uncertainties, along with the probability of occurrence of these pathways. The output of a climate change prediction is therefore a PDF of possible future climates, which can then be used in risk-based impact assessment studies. A measure of the width of this PDF (e.g. the standard deviation) is a measure of the uncertainty in the prediction.

What makes probabilistic prediction of climate change particularly difficult is that a large number of simulations are required to fully explore the phase space of possible future climates. In response to this need, efforts are currently under way to produce large ensembles of model simulations to generate climate change PDFs, such as the climateprediction.net (Stainforth et al. 2005) and CMIP3 (http://www.pcmdi.llnl. gov) projects. These ensembles provide information of unprecedented size and quality to characterize the uncertainty in climate change projections, particularly at sub-continental and regional scales.

Large ensembles of simulations and PDFs can also be completed using simple or intermediate complexity climate models (e.g. Wigley \& Raper 2001). Although these models can only provide reliable climate information at the global scale, some scaling properties of the regional climate change signal can be utilized to produce corresponding regional climate change projections (e.g. Mitchell 2003, Giorgi 2005b). Substantial research efforts are currently under way to produce probabilistic predictions of global and regional climates, and numerous methods have been proposed (e.g. Allen \& Stainforth 2002, Giorgi \& Mearns 2003, Murphy et al. 2004, Raisanen \& Ruokolainen 2006). Although much work still needs to be done in this regard, the availability of large ensembles of simulations is giving us a first glimpse of a coherent picture of climate change at sub-continental to regional scales, which is the topic of the next section.

\section{CLIMATE CHANGE SCENARIOS FROM THE GLOBAL TO THE REGIONAL SCALE}

Most current climate change experiments are based on the families of SRES GHG emission and concentra- tion scenarios developed by the IPCC (2000). These range from the low-end scenario $\mathrm{B} 1\left(\mathrm{CO}_{2}\right.$ concentration of $\sim 550$ by 2100 ) to the high-end scenario A1FI $\left(\mathrm{CO}_{2}\right.$ concentration of $\sim 950 \mathrm{ppm}$ by 2100). In the CMIP3 effort, over 20 AOGCMs worldwide were used to provide simulations of 20th and 21st century climate under 3 of these scenarios: the B1 (low end), A1B (middle of the range), and A2 (close to the high end).

As mentioned, the geographical patterns of change in sea level pressure, temperature, and precipitation simulated by an ensemble of models are relatively insensitive to the emission pathway, with the magnitude of change depending on the emission and concentration levels (Mitchell 2003, Giorgi 2005b). Therefore, in the present study we focus only on the last decades of the 21st century (e.g. 2071 to 2100 or 2081 to 2100) in the mid-range A1B emissions scenario and assume that, based on these scaling properties, similar change patterns are found for earlier decades and other scenarios, with the magnitude of change depending on the global temperature change (Mitchell 2003, Giorgi 2005b).

\subsection{Global climate model results}

The global model results discussed here are obtained from the CMIP3 dataset (http://www.pcmdi.llnl.gov) completed in support of the IPCC fourth assessment report (IPCC 2007). It is first useful to briefly comment on the global temperature projections. The IPCC (2001) identified a range of 1.4 to $5.8^{\circ} \mathrm{C}$ mean global temperature change by the end of the 21 st century compared to 2000. Although a direct comparison with IPCC (2001) is not possible, because of the different methodologies used to produce the projections, this estimated global warming range increases in IPCC (2007) to about 1.1 to $6.4^{\circ} \mathrm{C}$. This is mostly because some of the models in IPCC (2007) include interactive carbon cycle feedbacks (see Section 3), which generally lead to an increase of the spread in model response.

Figs. 2, $3 \& 4$, show the changes in surface air temperature (Tas), precipitation (Pr), and sea level pressure (Psl) (2071 to 2100 minus 1961-1990, A1B scenario) as derived from the CMIP3 ensemble for the two 6 mo periods from October to March and April to September. The geographical patterns of warming exhibit some well-known features: greater warming over land areas than over oceans and maximum warming over the high-latitude Northern Hemisphere regions in the boreal winter (due to the ice albedo feedback mechanism caused by melting of snow and sea ice).

Changes in Pr (Fig. 3) and Psl (Fig. 4) patterns reflect changes in large-scale circulations. We find a general trend of increased Psl, and thus increased subsidence 

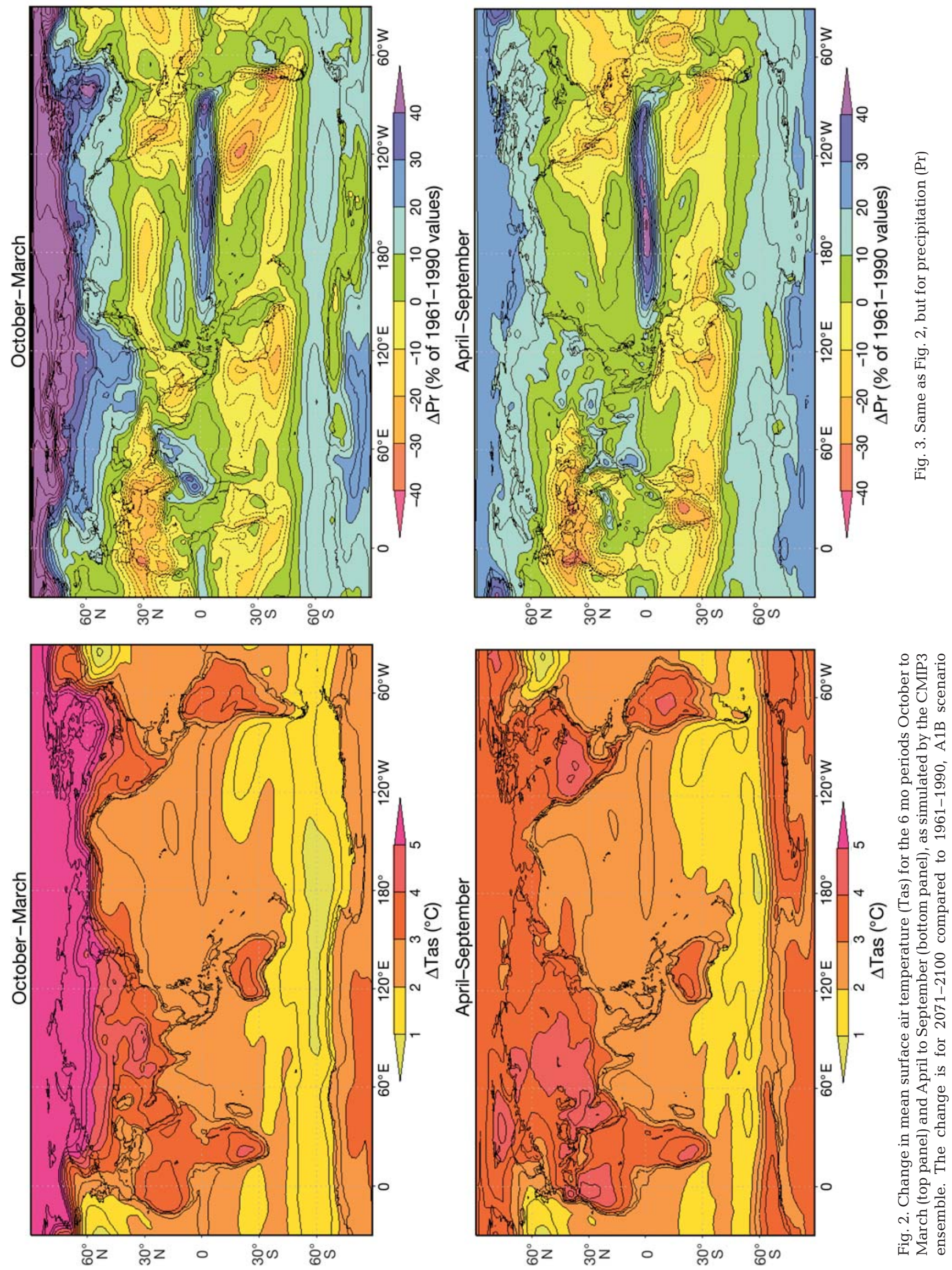
and anti-cyclonic circulation, over sub-tropical and mid-latitude regions, and decreased Psl (indicating increased cyclonic activity) over high-latitude regions. This indicates a poleward shift of the mid-latitude jet streams and storm tracks, which is essentially associated with larger mid-tropospheric warming at low latitudes compared to high latitudes (IPCC 2007). In response to this change, we find a general increase in precipitation over high-latitude regions and a decrease over sub-tropical regions. We also observe an increase in the intensity of the Inter-tropical Convergence Zone (ITCZ) and a corresponding increase in precipitation along the equatorial oceanic regions. This is due to higher sea surface temperature, evaporation, and convective activity there.

It is interesting to identify some particular regional change patterns. Two areas that emerge as being especially sensitive are the Mediterranean and Central America, where substantial decreases in precipitation are projected. Warming is also relatively high over these regions, particularly during their warm season. In fact, based on a multi-variable index, Giorgi (2006) identifies these regions as 2 of the most prominent climate change hotspots of the globe. These patterns have been observed in different generations of AOGCM climate change experiments (Kittel et al. 1998, Giorgi et al. 2001b) and thus appear to be robust.

An increase in monsoon precipitation over southern and eastern Asia is evident from the ensemble of models. Over Africa, the most prominent signals are an increase in precipitation over the eastern equatorial regions, particularly over the Lake Victoria region, and a decrease in precipitation over southern Africa, particularly in the cold season. For South America we find a seasonally and regionally more variable signal.

Changes in interannual variability are relevant for human health and disease. For instance, climate variability has been related to outbreaks of cholera (Pascual et al. 2000, Koelle et al. 2005), dengue fever (Gagnon et al. 2001), and malaria (Gagnon et al. 2002, Zhou et al. 2004). Fig. 5 shows the change in interannual variability of temperature and precipitation from the CMIP3 ensemble over the 26 land regions identified by Giorgi \& Bi (2005a) and Giorgi (2006). The interannual variability is calculated using $20 \mathrm{yr}$ periods (2081 to 2100 for future climate and 1961 to 1980 for present day climate) and is measured by the detrended interannual SD for temperature and by the de-trended coefficient of variation (the de-trended SD divided by the mean) for precipitation.

We find a predominant increase in interannual variability across regions, especially for precipitation. For temperature, variability increases in warm climate regimes, but decreases in a number of cold climate regional cases. These results are consistent with those
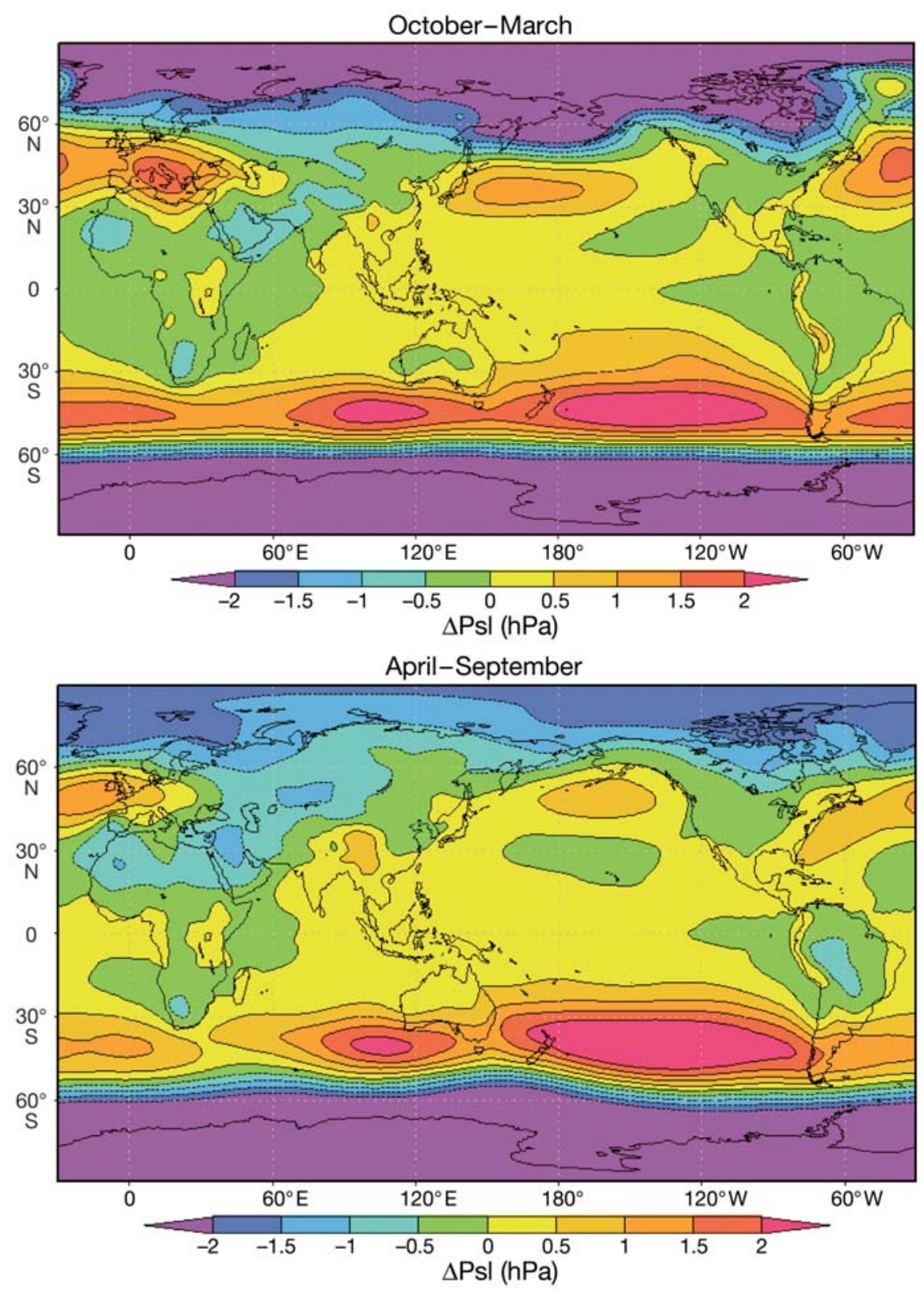

Fig. 4. Same as Fig. 2, but for sea level pressure, Psl 
Temperature

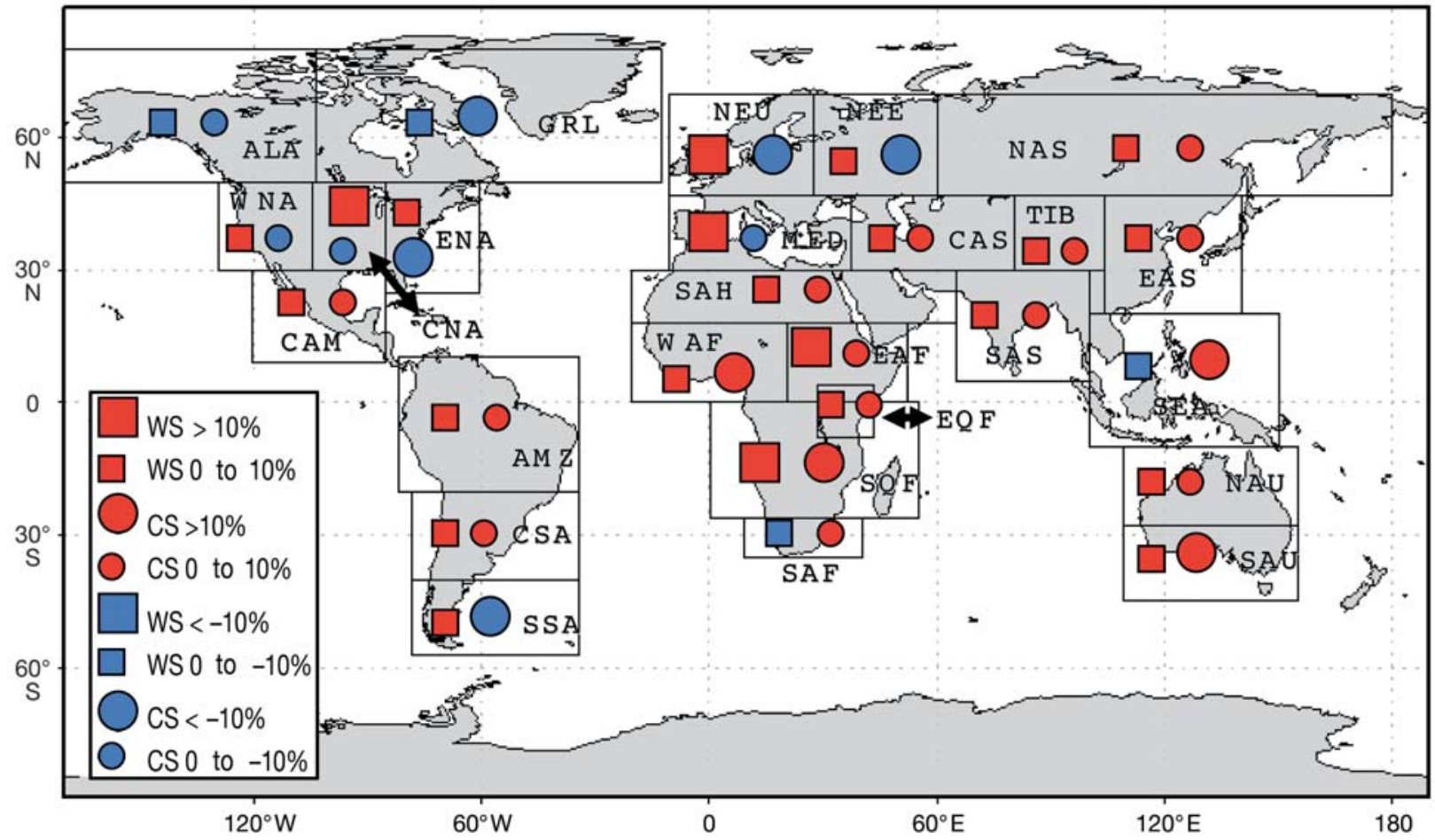

Precipitation

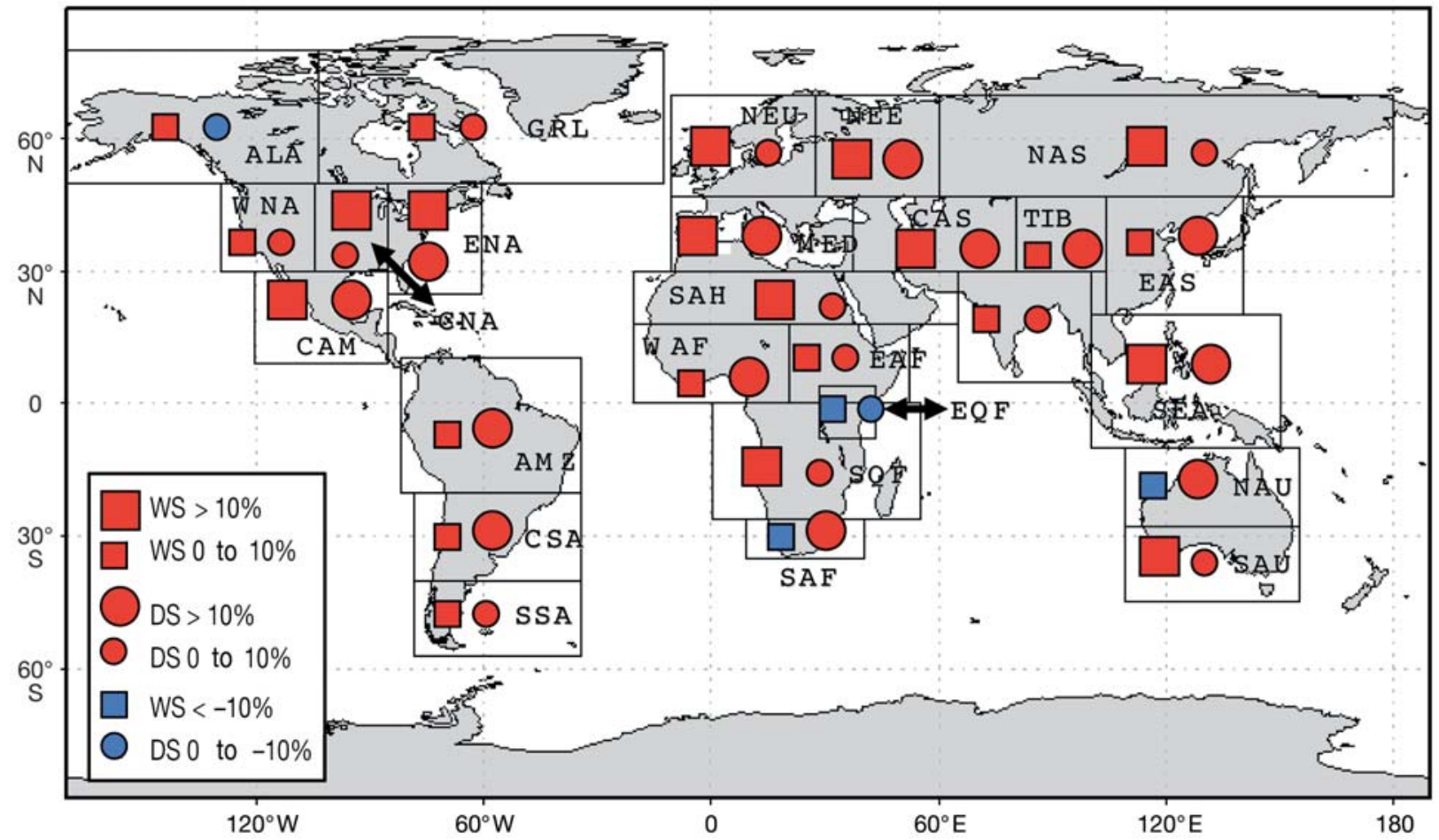

Fig. 5. Change in temperature (top panel) and precipitation (bottom panel) interannual variability over the 26 land regions of Giorgi \& Bi (2005a) as calculated from the CMIP3 ensemble for the A1B scenario. The changes are calculated for 2081-2100 compared to 1981-2000. The temperature interannual variability is measured by the interannual SD, while the precipitation variability is measured by the coefficient of variation. In the top panel WS and CS refer to the warm and cold, respectively, 6 mo season. In the lower panel WS and DS refer to the wet and dry, respectively, 6 mo season as defined by Giorgi \& Bi (2005a). Adapted from Table 1 in Giorgi (2006) 
of Raisanen (2002) and Giorgi \& Bi (2005b), obtained with previous model ensembles. Note that an increase in the warm season temperature variability along with a warming shift also leads to an increase in the occurrence of hot events. A general increase in warm climate interannual variability may be the result of an intensified hydrologic cycle and a drying of the continental interiors. For cold climate regimes, the reduction in variability may be associated with a reduction of snow cover and associated snow-albedo feedback mechanism (Raisanen 2002). Concerning ENSO, while the IPCC (2001) had projected an increase in the intensity of ENSO events, more recent work has called this conclusion into question (Collins et al. 2005). Therefore, it appears that projected changes in variability are not directly related to projected changes in ENSO characteristics.

A number of additional robust projected changes have also been identified by the IPCC (2007), that could impact human health and vector-borne disease: widespread increases in warm spells and heat waves, widespread decreases in cold events, increases in the intensity of precipitation events, increases in the intensity of storms, and increases in areas affected by droughts.

\subsection{Regional climate model results}

RCMs have been increasingly applied to climate change simulation over all land regions of the world, and we examine issues emerging from the production of RCM-based scenarios and their use in impact assessment studies. Although we focus on RCMs, similar conclusions can be found for other regionalization techniques.

A number of studies have clearly shown that fine-scale topographical features captured by RCMs substantially modulate the climate change signal, especially for precipitation (e.g. Giorgi et al. 1994, Diffenbaugh et al. 2005, Gao et al. 2006). Fig. 6 shows the winter and spring precipitation change in the high-resolution $(20 \mathrm{~km}$ grid spacing) climate change experiment over the Mediterranean region of Gao et al. (2006). Dipolar patterns of precipitation change can be observed across major mountain systems (e.g. the Alps and the Apennines) in response to changes in circulation. Precipitation shows a maximum increase on the upwind side of the mountains, with respect to the direction of the wind change, and shows a minimum increase or even a decrease on the downwind side. This is because of an increase in the occurrence of rain-producing upwind flow conditions with respect to the orientation of the mountain chains.

Several studies have also shown that topography affects the surface temperature change signal by inducing enhanced warming at high elevations due to
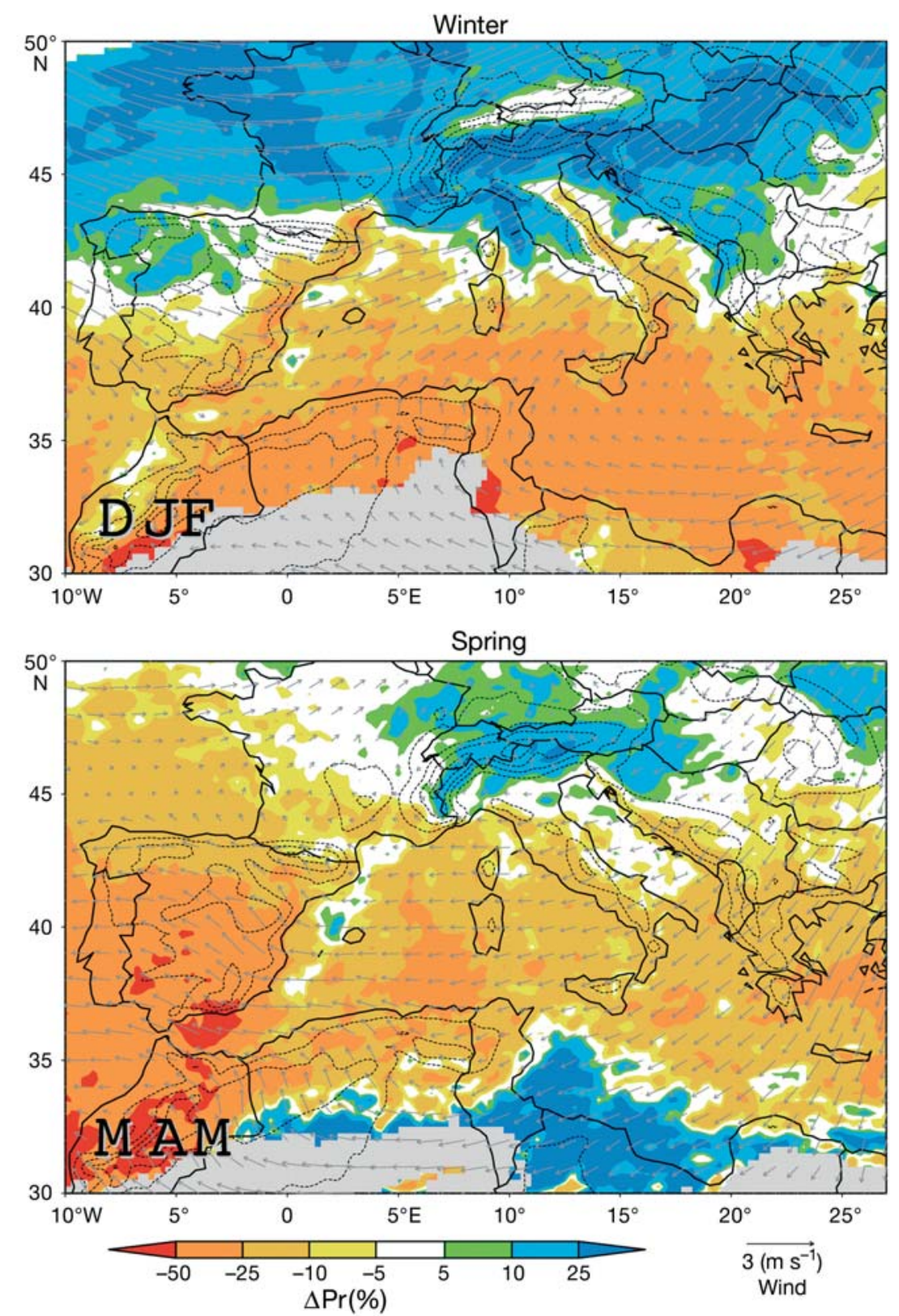

Fig. 6. Mean precipitation (Pr) change (winter in the upper panel [DJF], spring in the lower panel [MAM]) calculated in a high-resolution (20 km grid spacing) simulation over the Mediterranean region for the A2 IPCC emission scenario (2071-2100) compared to present day. The arrows show the change in low level wind. Adapted from Gao et al. (2006) 
the snow-albedo feedback mechanism (Giorgi et al. 1997, Fyfe \& Flato 1999). Since cool temperatures can limit parasite development in highland areas (Patz \& Reisen 2001), these fine-scale topography effects are important for assessing the potential for changes in disease vulnerability.

Likewise, RCMs have been shown to substantially improve the simulation of extreme events (e.g. highintensity precipitation) compared to lower resolution global models (e.g. Huntingford 2003). RCM experiments indicate that elevated GHG concentrations are likely to increase the frequency of extreme precipitation events, which could negatively impact human health by providing breeding grounds for disease vectors (Curriero et al. 2001, Shaman et al. 2002), but could also decrease vector survivorship (DeGaetano 2005). Additionally, projected increases in heat-wave frequency and severity (Pal et al. 2004, Schar et al. 2004, Diffenbaugh et al. 2005), as well as increased
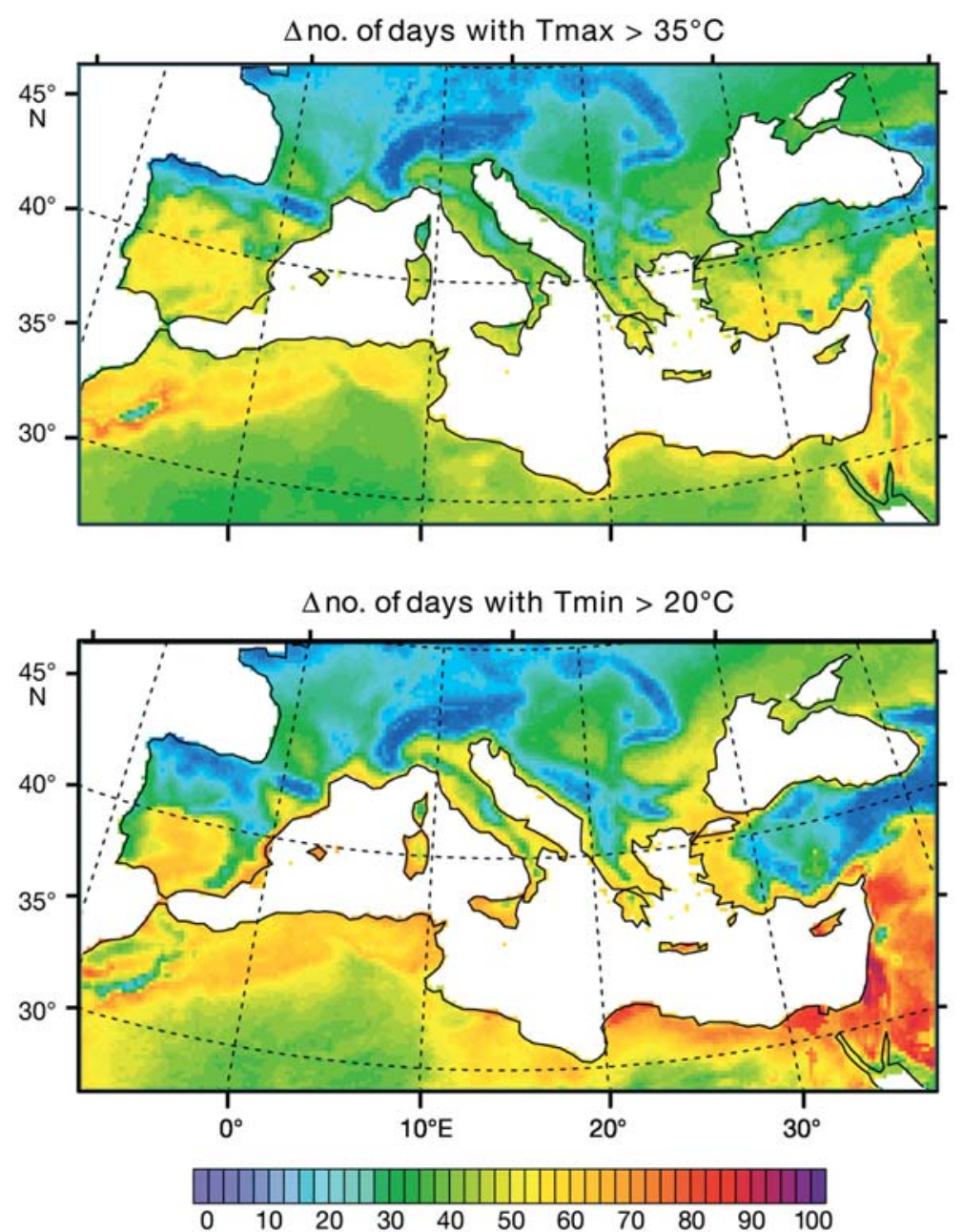

Fig. 7. Change in the number days with maximum daytime temperature $>35^{\circ} \mathrm{C}$ and minimum nighttime temperature $>20^{\circ} \mathrm{C}$ in the regional climate change simulations by Gao et al. (2006). The change is for 2071-2100 compared to 1961-1990 under forcing from the A2 emission scenario warm-season subsidence (Diffenbaugh et al. 2005), could be expected to impact human health by increasing heat-stress and pollution events (Kalkstein \& Greene 1997, Smoyer et al. 2000, Patz et al. 2005). Similarly, projected decreases in extreme cold events (Diffenbaugh et al. 2005) could decrease human mortality associated with severe cold (Kalkstein \& Greene 1997).

An example of the use of RCMs for health impacts is given in Fig. 7, which shows the change in the occurrence of days with temperature above given daytime and nighttime thresholds taken from the experiments by Gao et al. (2006). These thresholds were closely associated with heat-stress-related mortality during the European summer heat wave in 2003 (Grize et al. 2005, Poumadere et al. 2005). We highlight the finescale structure of the signal, with low elevation and coastal areas showing generally larger responses than high elevation areas.

Finally, RCMs also offer the opportunity to assess the potential dual impacts of changes in land cover and climate on human health. Not only can land cover directly influence disease outbreaks (Patz et al. 2004, Foley et al. 2005), but it can also influence local and regional climate, including temperature and precipitation extremes (Diffenbaugh 2005). Land-cover heterogeneity occurs at very fine spatial scales over much of the globe, and RCMs offer the potential to capture complex climate-land cover relationships that are often missed at the resolution of current GCMs.

\section{SUMMARY CONSIDERATIONS AND CONCLUSIONS}

Climate change induced by increased anthropogenic GHG concentrations has the potential to substantially impact the spread of climaterelated pathologies and vector-borne diseases. Temperature is one of the most important variables in determining heat-related health effects, as well as the activity of vectors for various diseases (e.g. malaria). The increase in temperature projected by virtually all models and scenarios, especially over land areas, could lead to a general spread of heat stress and vector-borne diseases, modifying the geographical distribution of the disease. In addition, changes in seasonality implied by the warming might alter the life cycle and spread of the disease vectors.

Effects related to precipitation change can be expected to vary regionally following the variations of the precipitation change signal. Specifi- 
cally, projections show substantial reduction of precipitation over many sub-tropical and adjacent regions, in particular the Mediterranean and Central America. Associated with a poleward shift of mid-latitude storm tracks, an increase of precipitation is projected over mid- and high-latitude regions. An increase in monsoon precipitation is projected over southern and eastern Asia, while a more mixed precipitation change signal is found over Africa and South America.

Model simulations also indicate a predominant increase in interannual variability, particularly in tropical regions and warm climate regimes. Recent studies indicate that climate variability may have a significant influence on disease outbreak, including cholera, dengue fever, and malaria, adding to the importance of climate change for this issue. The increase of variability along with shifts in climatic means can also lead to a substantial increase in the occurrence of extreme heat events. Many models show an increase of occurrence of heat waves and droughts (IPCC 2007), and this is likely to have strong implications for human health through heat-stress and pollution-related illness. Similarly, the intensity of precipitation events is projected to mostly increase, which might yield a greater occurrence of flooding episodes, which, in turn, could have large impacts on human health.

Changes in circulation regimes might affect in particular the spread of diseases whose vectors are carried by strong wind events (e.g. in the case of blue tongue disease), as well as heat-stress and pollution-related illnesses associated with subsidence and stagnation. In this regard, the most consistent signal shown by the model projections is a northward shift of the midlatitude jet streams and increased anticyclonic circulation and subsidence over many subtropical land areas.

Regional climate model simulations also indicate that the climate change signal is modulated by the effect of complex topography and coastlines. For example, surface warming tends to increase with elevation, which might lead to an enhanced migration of some diseases towards higher elevation environments. Similarly, the precipitation change signal is affected by the presence of topographical barriers. It is thus clear that an accurate assessment of the effect of climate change on disease spread requires high-resolution climate information.

It is important to emphasize that climate is only one of the factors that determine the spread of diseases or the severity of weather-related stresses (Hay et al. 2002, Patz et al. 2004, Koelle et al. 2005). The effect of climate change thus needs to be assessed within the context of multiple social, physiological, ecological, and environmental variables influencing human health and disease. Within this context, the availability of large ensembles of global and regional model simu- lations of increasing quality and resolution allows us today to obtain regional climate change information sufficiently comprehensive to better evaluate the role of climate in the future distribution of vector-borne diseases and heat-related stresses.

\section{LITERATURE CITED}

Allen MR, Stainforth DA (2002) Towards objective probabilistic climate forecasting. Nature 419:228

Collins WM and CMIP Modelling Groups (2005) El Nino- or La Nina-like climate change? Clim Dyn 24:89-104

Cubasch U, Waskewitz J, Hegerl G, Perlwitz J (1995) Regional climate changes as simulated in time-slice experiments. Clim Change 31:273-304

Curriero FC, Patz JA, Rose JB, Lele S (2001) The association between extreme precipitation and waterborne disease outbreaks in the United States, 1948-1994. Am J Public Health 91:1194-1199

> DeGaetano AT (2005) Meteorological effects on adult mosquito (Culex) populations in metropolitan New Jersey. Int J Biometeorol 49:345-353

Deque M, Piedelievre JP (1995) High resolution climate simulation over Europe. Clim Dyn 11:321-339

Diffenbaugh NS (2005) Sensitivity of extreme climate events to $\mathrm{CO}_{2}$-induced biophysical atmosphere-vegetation feedbacks in the western United States. Geophys Res Lett 32:L07702

> Diffenbaugh NS, Pal JS, Trapp RJ, Giorgi F (2005) Fine-scale processes regulate the response of extreme events to global climate change. Proc Natl Acad Sci USA 102: 15774-15778

Diffenbaugh NS, Pal JS, Giorgi F, Gao X (2007) Heat stress intensification in the Mediterranean climate change hotspot. Geophys Res Lett 34:L11706

Foley JA, de Fries R, Asner GP, Barford C and others (2005) Global consequences of land use. Science 309:570-574

Friedlingstein P, Bopp L, Rayner P, Cox P (2006) Climate-carbon cycle feedback analysis: results from the (CMIP)-M-4 model intercomparison. J Clim 19:3337-3353

Fyfe JC, Flato GM (1999) Enhanced climate change and its detection over the Rocky Mountains. J Clim 12:230-243

Gagnon AS, Bush ABG, Smoyer-Tomic KE (2001) Dengue epidemics and the El Nino Southern Oscillation. Clim Res 19:35-43

Gagnon AS, Smoyer-Tomic KE, Bush ABG (2002) The El Nino Southern Oscillation and malaria epidemics in South America. Int J Biometeorol 46:81-89

Gao X, Pal JS, Giorgi F (2006) Projected changes in mean and extreme precipitation over the Mediterranean region from high resolution double nested RCM simulations. Geophys Res Lett 33:L03706

Giorgi F, Hewitson B, Christensen M, Hulme H and others (2001a) Regional climate information-Evaluation and projections. In: Houghton JT, Ding Y, Griggs DJ, Noguer $M$ and others (eds) Climate change 2001: the scientific basis. Intergovernmental Panel on Climate Change (IPCC), Cambridge University Press, Cambridge, p 583-638

Giorgi F, Whetton PH, Jones RG, Christensen JH and others (2001b) Emerging patterns of simulated regional climatic changes for the 21st century due to anthropogenic forcings. Geophys Res Lett 28:3317-3320

Giorgi F (2005a) Climate change prediction. Clim Change 73:239-275

Giorgi F (2005b) Interdecadal variability of regional climate 
change: implications for the development of regional climate change scenarios. Meteorol Atmos Phys 89:1-15

Giorgi F (2006) Climate change hot-spots. Geophys Res Lett 33:L08707

- Giorgi F, Bi X (2005a) Regional changes in surface climate interannual variability for the 21 st century from ensembles of global model simulations. Geophys Res Lett 32: L13701

Giorgi F, Bi X (2005b) Updated regional precipitation and temperature changes for the 21st century from ensembles of recent AOGCM simulations. Geophys Res Lett 32: L21715

Giorgi F, Francisco R (2000) Uncertainties in regional climate change prediction: a regional analysis of ensemble simulations with the HADCM2 coupled AOGCM. Clim Dyn 16:169-182

Giorgi F, Mearns LO (2003) Probability of regional climate change calculated using the Reliability Ensemble Averaging (REA) method. Geophys Res Lett 30:1629

Giorgi F, Shields Brodeur C, Bates GT (1994) Regional climate change scenarios over the United States produced with a nested regional climate model. J Clim 7:375-399

> Giorgi F, Hurrell JW, Marinucci MR, Beniston M (1997) Elevation signal in surface climate change: a model study. J Clim 10:288-296

Grize L, Huss A, Thommen O, Schindler C, Braun-Fahrländer C (2005) Heat wave 2003 and mortality in Switzerland. Swiss Med Wkly 135:200-205

Harvell CD, Mitchell CE, Ward JR, Altizer S and others (2002) Climate warming and disease risks for terrestrial and marine biota. Science 296:2158-2162

Hay SI, Cox J, Rogers DJ, Randolph SE and others (2002) Climate change and the resurgence of malaria in the East African highlands. Nature 415:905-909

Hewitson BC, Crane RG (1996) Climate downscaling: techniques and application. Clim Res 7:85-95

Huntingford C (2003) Regional climate model predictions of extreme rainfall for a changing climate. Q J R Meteorol Soc 123:265-292

IPCC (Intergovernmental Panel on Climate Change) (2000) Special report on emission scenarios. Cambridge University Press, New York

IPCC (Intergovernmental Panel on Climate Change) (2001) Climate change 2001: the scientific basis. Cambridge University Press, Cambridge

IPCC (Intergovernmental Panel on Climate Change) (2007) Climate change 2007: the physical science basis. Summary for policymakers. Available at: www.ipcc.ch

Kalkstein LS, Greene JS (1997) An evaluation of climate/ mortality relationships in large US cities and the possible impacts of a climate change. Environ Health Perspect 105: 84-93

Kittel TGF, Giorgi F, Meehl GA (1998) Intercomparison of regional biases and doubled $\mathrm{CO}_{2}$ sensitivities of coupled atmosphere-ocean general circulation model experiments. Clim Dyn 14:1-15

Koelle K, Rodo X, Pascual M, Yunus M, Mostafa G (2005) Refractory periods and climate forcing in cholera dynamics. Nature 436:696-700

Marra PP, Griffing S, Caffrey CL, Kilpatrick $M$ and others (2004) West Nile virus and wildlife. Bioscience 54:393-402

McMichael AJ, Woodruff RE, Hales S (2006) Climate change and human health: present and future risks. Lancet 367 : 859-869

Mearns LO, Hulme M, Carter TR, Leemans $\mathrm{R}$ and others (2001) Climate scenario development. In: Houghton JT,
Ding Y, Griggs M, Noguer PJ and others (eds) Climate change 2001: the scientific basis. Intergovernmental Panel on Climate Change (IPCC), Cambridge University Press, Cambridge, p 583-638

Mitchell TD (2003) Pattern scaling. An examination of the accuracy of the technique for describing future climates. Clim Change 60:217-242

Murphy JM, Sexton DMH, Barnett DN, Jones GS and others (2004) Quantification of modelling uncertainties in a large ensemble of climate change simulations. Nature 430: 768-772

Pal JS, Giorgi F, Bi XQ (2004) Consistency of recent European summer precipitation trends and extremes with future regional climate projections. Geophys Res Lett 31:L13202

Pascual M, Rodo X, Ellner SP, Colwell R, Bouma MJ (2000) Cholera dynamics and El Nino-Southern Oscillation. Science 289:1766-1769

Patz JA, Daszak P, Tabor GM, Alonso Aguirre A and others (2004) Unhealthy landscapes: policy recommendations on land use change and infectious disease emergence. Environ Health Perspect 112:1092-1098

> Patz JA, Reisen WK (2001) Immunology, climate change and vector-borne diseases. Trends Immunol 22:171-172

Patz JA, Campbell-Lendrum D, Holloway T, Foley JA (2005) Impact of regional climate change on human health. Nature 438:310-317

Poumadere M, Mays C, Le Mer S, Blong R (2005) The 2003 heat wave in France: dangerous climate change here and now. Risk Anal 25:1483-1494

Raisanen J (2002) $\mathrm{CO}_{2}$ induced changes in interannual temperature and precipitation variability in 19 CMIP2 experiments. J Clim 15:2395-2411

Raisanen J, Ruokolainen L (2006) Probabilistic forecasts of near-term climate change based on a resampling ensemble technique. Tellus A 58:461-472

Randall D, Wood R, Bony S, Colman R and others (2007) Climate models and their evaluation. In: Solomon S, Qin D, Manning $M$, Marquis $M$ and others (eds) Climate change 2007: the physical science basis. Intergovernmental Panel on Climate Change (IPCC), Cambridge University Press, Cambridge, p 583-638

Rogers DJ, Randolph SE (2000) The global spread of malaria in a future, warmer world. Science 289:1763-1766

Schar C and others (2004) The role of increasing temperature variability in European summer heatwaves. Nature 427: 332-336

Shaman J, Stieglitz M, Stark C, Le Blancq S, Cane M (2002) Using a dynamic hydrology model to predict mosquito abundances in flood and swamp water. Emerg Infect Dis 8:6-13

Smoyer KE, Kalkstein LS, Greene JS, Ye HC (2000) The impacts of weather and pollution on human mortality in Birmingham, Alabama and Philadelphia, Pennsylvania. Int J Climatol 20:881-897

Stainforth DA, Aina T, Christensen C, Collins M and others (2005) Uncertainty in predictions of climate response to rising levels of greenhouse gases. Nature 433:403-406

Wigley TML, Raper SCB (2001) Interpretation of high projections for global mean warming. Science 293:451-454

Zell R (2004) Global climate change and the emergence/reemergence of infectious diseases. Int $\mathrm{J}$ Med Microbiol 293:16-26

Zhou G, Minakawa N, Githeko AK, Yan GY (2004) Association between climate variability and malaria epidemics in the East African highlands. Proc Natl Acad Sci USA 101:2375-2380

Submitted: August 23, 2007; Accepted: December 9, 2007 Proofs received from author(s): March 11, 2008 